\title{
Patients' experiences in a newly established clinic for late complications after colorectal and anal cancer treatment: a qualitative study
}

Birthe Thing Oggesen ( $\nabla$ birthe.thing.oggesen@regionh.dk)

Herlev Hospital https://orcid.org/0000-0002-5722-4393

Momena Akbar

Sjællands Universitetshospital Køge: Sjaellands Universitetshospital Koge

Marie Louise Sjødin Hamberg

Herlev Hospital

Anne Kjaergaard Danielsen

Herlev Hospital

Thordis Thomsen

Herlev Hospital

Jacob Rosenberg

Herlev Hospital

\section{Research Article}

Keywords: Late complication, Colorectal cancer, Survivorship, Outpatient clinic,

Posted Date: January 14th, 2022

DOI: https://doi.org/10.21203/rs.3.rs-1144967/v1

License: (1) This work is licensed under a Creative Commons Attribution 4.0 International License.

Read Full License 


\section{Abstract \\ Purpose}

Treatment of late complications is not systematically provided in Denmark. We therefore established a clinic to treat patients' late complications. With this study we wanted to explore patients' experiences with treatment and care in the clinic, including their recommendations for the future organization and structure of the clinic.

\section{Methods}

We conducted a qualitative semi-structured interview study with patients who had attended our late complication clinic after treatment for colorectal or anal cancer.

\section{Results}

We included 14 patients. We found two main categories: 1: benefitting from the late complication clinic and 2: preparation and delivery of the consultations. Patients benefitted from attending the late complication clinic and some experienced complete relief from symptoms. Others did not, but they gained hope that they might be able to receive treatment in the future. Patients wished for more information about late complications, preferring that the most common symptoms were described along with patient-friendly treatment options. The patients were satisfied with telephone consultations, as they were easy to fit into a daily schedule, and patients found it easy to express themselves openly.

\section{Conclusions}

Patients were satisfied with the late complication clinic as they felt it gave them a safety net. For the future, patients recommended provision of more information about late complications and possible treatments.

\section{Introduction}

Colorectal cancer is one of the most common cancer types in the world with 1.93 million new cases worldwide every year [1]. The survival rates are quite good; for colon cancer the five-year survival rate is $65-73 \%$ and for rectum cancer it is $73 \%[2,3]$. The worldwide incidence of anal cancer is much lower with 50,000 new cases every year and the five-year survival rate is $66 \%$ [1]. During the last years it has become common knowledge to the clinical community that late complications after treatment for colorectal and anal cancer are frequent [2-8]. However, well-established clinics as well as treatment options for late complications based on scientific evidence are scarce [8, 9]. In our surgical department at a tertiary university hospital we established a nurse-led clinic for handling late complications after colorectal-and 
anal cancer treatment. In the clinic, we identify and treat late complications based on treatment guidelines developed specifically for the most common symptoms seen in the clinic.

To optimize the treatment of patients with late complications, this study aimed to explore patients' experiences with treatment and care for late complications in the clinic. We also wanted to gain insight into patients' recommendations for the future organization and structure of the clinic.

\section{Methods}

All patients in our department undergoing surgery for colorectal and anal cancer after October 2019 were invited to attend our late complication clinic three months after surgery. The patients were invited digitally through patients' personal secure electronic mailbox [10]. They were asked to fill out Patient Reported Outcome Measures (PROMs) concerning various symptoms of late complications, and if they wanted, they could indicate whether they wished to be contacted by the clinic by phone. Patients who had surgery before October 2019 or who only had oncological treatment could be referred to the late complication clinic by other clinicians. These patients were also asked to fill out PROMs prior to visiting our clinic.

We performed a qualitative semi structured interview study with a descriptive approach focusing on patients' perceptions and experiences related to the provision of treatment in the late complication clinic. To ensure credibility, transferability, dependability and confirmability [11] we have detailed the methodological steps of the study, from the planning of the study to writing up of findings. Furthermore, the study is reported according to the Consolidated Criteria For Reporting Qualitative Research guidelines (COREQ) [12].

All participants were patients in an out-patient clinic for late complications after treatment for colorectal or anal cancer. The inclusion of patients was based on principles of purposeful sampling [13], and patients were selected according to gender, symptoms, age, and number of contacts with the clinic. Moreover, all patients were over 18 years old, able to communicate sufficiently in Danish, and willing to participate in an interview session about their experiences in the late complication clinic. All patients were recruited while in the late complication clinic attending a consultation. Patients were purposefully included to gain a broad spectrum of age groups and symptoms.

The interviews were conducted by two interviewers (MLH and TT), who did not have prior knowledge of the patients and had no clinical experience from working in the clinic. This was done to avoid positive or negative feedback influencing the interviewers and thereby outcome of the interviews. All interviews were conducted in Danish by telephone in order to counter problems related to the current COVID-19 pandemic. The interviews were guided by a semi-structured interview guide based on a thorough literature search and discussions among clinicians involved in the development of the late complication clinic. It covered experiences in the clinic including use of e-PROMS, treatment by the nurse or the doctor, effect of attending the clinic, and patients' recommendations for improving the setup in such a clinic, including suggestions for future development of the organizational structure. The study was exploratory, guided by focused questions and respectful probing of answers given by the participants; especially answers that 
we found surprising. In consistency with an exploratory approach, the interviews began with broad and open questions to allow participants to become accustomed to the situation so they would fully articulate their experiences [14]. Subsequently, the semi-structured interview guide with open-ended questions was applied to direct the dialogue $[15,16]$. The number of participants was guided by the principle of data saturation, which in this study was assessed during the conduct of interviews as well as during the analysis of data [17]. As such, agreement on data saturation was reached through a reflective process in the research group and was obtained when all experienced data became redundant.

The interviews were transcribed in full [18] and analyzed using qualitative content analysis [19]. The inductive analysis was done in a parallel process by two researchers (BTO and MA), with the final analysis using a joint document. The full text transcripts were read, and notes and headings were written in the text while reading it. From these notes and headings initial categories were identified. We reduced the number of categories by collapsing those that were similar into broader higher order categories. Both interviewers and researchers met to discuss the major findings and agreed on the final categories.

All patients were included after informed consent. Information about the interview was given either by telephone or by electronic communication to the patient's personal secure electronic mailbox [10]. All patients were informed about anonymity and confidentiality, and it was underlined that participation was voluntary and that they could withdraw from the study with no consequence for their future treatment in the clinic. All patients were informed that interviews were recorded. The study was approved by the Danish Data Protection Agency (P-2021-31) and was exempt from approval from the Committee of Health Research Ethics (Journal-no.: H-21020718). The study was done in full accordance with the Helsinki declaration [20].

\section{Results}

We included 15 patients, but one patient withdrew consent before the interview because he did not have the time to participate leaving 14 patients for data analysis. All interviews were performed from June 2021 to August 2021, and the interviews had a median duration of 30 minutes (range 18-49 minutes). The patients represented different symptoms, age groups and genders (Table 1). Results are reported according to major findings and noted as final categories identified during the analysis (Figure 1). 
Table 1

Demographics.

\begin{tabular}{|c|c|c|c|c|c|}
\hline $\begin{array}{l}\text { ID } \\
\text { number }\end{array}$ & Gender & Age & Cancer form & Symptoms* & $\begin{array}{l}\text { Number of } \\
\text { contacts } *\end{array}$ \\
\hline 1 & Male & 59 & $\begin{array}{l}\text { Rectum } \\
\text { cancer }\end{array}$ & Stool & 3 \\
\hline 2 & Male & 65 & Colon caner & Stool & 2 \\
\hline 3 & Male & 75 & $\begin{array}{l}\text { Rectum } \\
\text { cancer }\end{array}$ & Stool, urine & 3 \\
\hline 4 & Male & 58 & Colon cancer & Psycho-social & 1 \\
\hline 5 & Female & 75 & Anal cancer & Stool, urine & 2 \\
\hline 6 & Female & 73 & Colon cancer & Stool & 1 \\
\hline 7 & Female & 55 & Colon cancer & Urine, psycho-social & 1 \\
\hline 8 & Male & 59 & $\begin{array}{l}\text { Rectum } \\
\text { cancer }\end{array}$ & Stool & 4 \\
\hline 9 & Male & 74 & Colon cancer & Stool, psycho-social & 3 \\
\hline 10 & Male & 56 & Anal cancer & Stool, psycho-social & 6 \\
\hline 11 & Male & 76 & $\begin{array}{l}\text { Rectum } \\
\text { cancer }\end{array}$ & $\begin{array}{l}\text { Stoll, urine, sexual, psycho- } \\
\text { social }\end{array}$ & 6 \\
\hline 12 & Male & 52 & $\begin{array}{l}\text { Rectum } \\
\text { cancer }\end{array}$ & Stool, sexual & 2 \\
\hline 13 & Female & 60 & $\begin{array}{l}\text { Rectum } \\
\text { cancer }\end{array}$ & Stool & 4 \\
\hline 14 & Male & 70 & $\begin{array}{l}\text { Rectum } \\
\text { cancer }\end{array}$ & Stool & 2 \\
\hline 15 & Female & 42 & Anal cancer & Stool & 3 \\
\hline
\end{tabular}


Table 2

Citations.

$\begin{array}{lll}\text { Subcategories Citation } & \begin{array}{l}\text { Participant } \\ \text { number }\end{array}\end{array}$

How the patients

I have been in a kind of vacuum. I did not know what was

10

got in contact with

the clinic

happening with me. I have these visits (at oncology department)

three times a year at Herlev (name of the hospital), I tell my

complaints and such things. And then suddenly she says "you

know what, we will give you, that you can attend the late

complication clinic".

Professional staff

It was super good, I have had really good information. Now we

2

do so, I will call you etc. Good treatment, good guidance, and good in listening, they are too.

Symptoms were reduced for most patients after they had attended the late complication clinic
I went home with a treatment plan, and then she has continuously followed up on how this treatment plan worked for me. It was very nice from the beginning to have outlined what to do next if the first step did not work. And to know I would not reach a sorry state if the first treatment did not work.
Experiences with the concept of a late complication clinic
It is difficult for a person like me to keep track on whom I am supposed to contact and where I shall address a specific problem, but (with the late complication clinic) there is one gateway and then they will sort out what to do.
Recommendations for the future of the clinic
I would like to have advice and guidance to get started (treatment of late complication). I would also like to have advice and guidance to what I could expect. In coherency with that there should be a follow-up asking how it is going. I suppose there would be more need for follow up in the beginning than later.
Consultations by telephone
I prefer telephone consultation because I think it is so troublesome to come to Herlev (name of the hospital). Yes, because then I only spend one hour, or half an hour if the consultation last that long. Otherwise I could spend the entire morning.
Experiences with ePROMS
If I had the same questions before my surgery for cancer it would have crossed my personal boundary to answer, but it was in fact nice to have the possibility to answer in so much detail.

\section{How the patients got in contact with the clinic}

It was difficult for patients to differentiate between the various out-patient clinics they attended in the hospital care system. At our Department of Surgery all patients routinely attend follow up care primarily to check for recurrence. Some patients also had appointments at the oncology and general medical departments. The late complication clinic was an add-on offer to detect and treat late complications. All patients in the current interview study had attended the late complication clinic, however with diverse 
points of entry into the clinic and subsequently quite different perceptions of how they came into the clinic. Patients who were referred to the late complication clinic by the oncologist knew when and how they came into the clinic contrary to patients who were referred immediately after surgery. The latter were invited through ePROMs according to the current point of entry set up for the clinic. Interestingly, one participant was convinced that he or she had never been to the clinic. In general, the patients found it difficult to find information about the clinic on the hospital's website.

\section{Professional staff}

The patients experienced the staff as professional and with excellent communication skills, proficient dissemination of knowledge, good at asking questions, and they welcomed all questions - even the strangest ones as a participant formulated it. Patients were able to prioritize their problems while in the clinic. The patients described having different experiences with the one surgeon and two specialized nurses dedicated to manning the clinic. Some patients were very happy to talk with the surgeon during the first consultation while others experienced that the surgeon's guidance did not work, and they were happier with guidance from the nurses.

Some perceived they were discharged from late complication clinic prematurely and felt rejected by the staff. They wanted a future appointment in the clinic instead of merely the possibility to contact the clinic by telephone if they experienced symptom relapse or new symptoms. Surprisingly, some patients expressed that they had not been informed that they could always call the clinic if needed.

Symptoms were reduced for most patients after they had attended the late complication clinic

Most patients felt benefit from attending the late complication clinic. They primarily received help with stool problems, which eased their everyday living. Common stool problems were diarrhea or fecal incontinence which were addressed by medical advice and general advice about food intake and toilet habits. The patients had two different observations regarding how they were informed about treatment options. Some experienced they were informed precisely about dosage of medications and provided with a detailed treatment guide. They also learned that there were alternative options if the first treatment did not work. Others felt they had to improvise and find the correct dosage of medicine through a trial and error process. Thus, they wished for more concrete advice.

Many patients were experienced in taking stool regulation medicine prior to their contact with the late complication clinic. Despite this, they described how they were first able to identify the appropriate dose after being guided and titrated by the staff in the clinic.

Patients who had no effect of treatment from the clinic expressed that although they were not relieved of their stool problems they were helped in other ways, which reduced challenges in their daily life. Some expressed that they had received dietary advice that although it did not help patients fully, it nevertheless contributed to some symptom relief. Patients anticipated that, hopefully, at some point the advice would help them, or a new effective treatment would emerge. 
Some patients had the perception that the clinic only took care of bowel symptoms, and they therefore refrained from asking for help for other symptoms. However, other patients described they were helped with other symptoms as well, for example erectile dysfunction.

Experiences with the concept of a late complication clinic

The patients' experiences with the late complication clinic were diverse. Many patients were delighted with the clinic since the majority had managed on their own for a long period of time without knowing where they could get help before they were referred to the late complication clinic. Others had so many offers and appointments at the hospital that it was difficult for them to discern if they were in the late complication clinic or in the ordinary cancer control program. Regardless of this, they declared they were satisfied with either clinic they attended.

Generally, the patients expressed that they felt very secure knowing they had the late complication clinic as a backup. This sensation of feeling secure was expressed in different ways: they were not forgotten, and they appreciated that somebody would help them if needed. Moreover, patients were glad to be in any new projects and they were willing to do something extra if they could contribute to science. Additionally, they had a feeling of better information and getting better service with more consultations when they were in a project.

Recommendations for the future clinic

All patients expressed the need to be referred to a late complication clinic after treatment for colorectal and anal cancer. Either they wished to be connected immediately after initial treatment or 3-6 months after. If they were referred to the clinic right after treatment, they would expect counseling from the beginning about which complications and symptoms were most common. They would feel very secure due to the contact with the clinic. Notably, patients underlined the importance of getting help at the outset of treatment in order to avoid developing bad habits or inventing self-made strategies to treat late complications. Others argued that if they were seen before three months, they would not have late complications yet. Some thought there were already too many adjustments to deal with in the patient's life right after treatment, and they would not be ready to attend a new clinic at that point.

All patients were asked if they would attend an information session with other patients about late complications if that was possible. Most patients would like contact with other patients, but the majority of the patients preferred small groups with 2-3 participants who had undergone the same kind of surgery, and who had similar late complications. Yet, others had a good experience with the patient education they had attended before surgery. This education normally entailed education of 10-15 patients about what to expect at the time of admission and surgery. The patients expressed they would like a similar setup concerning late complications and treatment options. Among the patients who would opt to attend an information session, most said they would not actively partake in an open discussion or information session about taboo subjects such as stool problems. 
Several patients recommended more information material to be available either as a brochure or on the hospital's website. They wished for information about the most common late complications such as how long time the symptoms would persist, dietary advice, and treatment options that the patient could start up on their own. Patients also wanted us to share general advice from other patients even though they knew that such advice was not necessarily evidence based.

Some of the men pointed out that they would benefit from offers directed to the male gender. It was not specified what they exactly wanted, but they mentioned more concrete advice and information. They would prefer that more information was separated by gender and more men than women were willing to help other men through peer support in the future.

Preparation and delivery of the consultations

Consultations by telephone

Almost all consultations in the late complication clinic were conducted by telephone. Most patients appreciated this because it was practical when they lived far away from the hospital, it eliminated time for transport, and it was easier to fit into everyday life with a job and other activities. Some patients preferred face-to-face contact because they wanted to know the staff better and because it was easier to bring a relative to a face-to-face consultation. However, the patients who preferred physical contact also accepted telephone consultations. Some patients even announced that they favored telephone consultations over video consultations. In general, patients found it easy to express themselves over the telephone.

Experiences with ePROMS

All patients filled out ePROMs before they came to the clinic, and they had no problem in answering the questions. Almost all patients mentioned that there were many questions. For the vast majority, it was not a problem and they understood that we needed to ask many questions to cover the subject and to contribute to research. Patients experienced a positive reflection of their situation with symptoms of late complications while answering the questions. A few well educated patients were worried that the questions were too many and too difficult to answer for patients with lower educational levels. Some patients missed more purposeful questions about psychiatric reactions and lifestyles habits.

\section{Discussion}

Patients were very satisfied with the existence of a late complication clinic. With this clinic the patients had a safety net, and they could always contact the clinic if they were in doubt or insecure about symptoms or treatment. Furthermore, they felt that the staff were professional. When asking patients about possible future directions for the clinic, they opted for much more information about any aspect of survivorship after colorectal- and anal cancer. Furthermore, they wanted different and more individualized ways of communicating with the staff. Patients were positive about telephone consultations because 
they were time saving and they felt they could express themselves more freely. In addition, the patients with late complications after colorectal and anal cancer often have stool incontinence, and for them it must be easier to attend a consultation from home near to the toilet instead of spending time on transport and waiting in the outpatient clinic with the risk of stool-accidents.

Both patients who had good effect of treatment but also patients with some or no effect were satisfied with the clinic. We find this interesting, and it suggests that patients who have undergone cancer treatment accept that they may have irreversible late complications. Possibly, patients feel they have been threatened on their life owing to the cancer and are therefore thankful that they survived and are thereby willing to accept late complications. Others with the same perception of survival could notoriously decide to have a more positive view of life, as a reaction to getting a second chance in life. Another aspect is that more patients had symptoms for a longer period before they attended the late complication clinic. Upon meeting healthcare professionals who listened to their problems and helped them without giving up on them, they became hopeful for the future and this itself could make them more satisfied even though they still experienced symptoms.

All the patients who attended the late complication clinic filled out an ePROM. In this interview study, patients understood and were willing to answer many questions to contribute to research. The patients also experienced that the questions enhanced their own understanding of symptoms and helped them prepare for the consultation in the clinic. As clinicians we used the ePROMs actively in our consultation, finding them very helpful for guiding the consultation. Patients were prepared to prioritize problems, and we found it much easier to talk about taboo subjects like stool incontinence and sexual dysfunction because both the patient and clinician had read the ePROM before the consultation.

Patients had different views on the optimal timing of when to attend the late complication clinic. This is not surprising, as patients may have different perceptions of what have happened during treatment, and they may have different late complications despite having had the same disease and initial treatment. Furthermore, it seems that some complications after treatment for cancer may regress during the first 3-6 months, e.g. acute cutaneous reactions after radiation therapy [21] and neuropathy after chemotherapy [22]. Other complications are advantageously treated from the beginning to get the best results, e.g. erectile dysfunction [23]. Other symptoms are not yet fully investigated, e.g. bowel symptoms, but it seems that stool problems do not regress without intervention, at least after right sided colon resection [5]. The optimal time for initiation of intervention for late complications is therefore not clear, but should be something between 14 days to 6 months after surgery.

Several patients had difficulty distinguishing between the late complication clinic and the ordinary outpatient clinic for follow-up after cancer. Patients who came to the clinic months or years after cancer treatment were very much aware of what the late complication clinic was. However, patients who were automatically enrolled in the clinic close to their cancer treatment were less aware of which clinic they attended. Cancer treatment is complex and so is the follow-up. Therefore, it is understandable that patients become confused about different clinics and different offers [24]. 
Strengths of this qualitative study were that we aimed at a high degree of quality and to ensure credibility we involved the staff in the late complication clinic to confirm the interview guide was in accordance with the daily work in the clinic. All participants were informed that the interviews were anonymous, and they could withdraw consent at any point. Furthermore, the participants were informed that the interviewer did not work in the late complication clinic, and they could talk freely of any experiences they had had. The results are likely transferable to other clinics and patients since patients are treated similarly for colorectal and anal cancer with surgery and or chemo-radiation therapy in most parts of the world. We collected data using telephone interviews and this has been described as an advantageous method within qualitative research due to the ease of access to the patients and thereby possibility to prevent dropouts [25], and it might even facilitate disclosure of sensitive information [26]. Moreover, we used recognized methods in the study design. Furthermore, we included patients according to different ages, gender, symptoms, and number of contacts to the clinic. This contributed to a broad representation of the patients in the late complication clinic (Table 1). Limitations of this qualitative study include lack of a more explorative interview for certain subjects, for example why patients would not actively partake in an open discussion during an information session and what it would take to partake in an open discussion. It would also be interesting to further explore what men lacked in the late complication clinic and what they would recommend for the future clinic. Unfortunately, this was not clear to the study group before completion of the analyses and writing of the final results.

Patients were confused about which clinic they attended and what help they could get and they also lacked information about late complications either from brochures or websites. In our clinic, we want to unfold these aspects. One way to achieve this could be better decision-making tools to help the patients prioritize problems and options according to what they experience and feel and not according to what they think a specific clinic can or cannot offer. Additionally, the patients need information and it is important to direct this to the platforms patients use.

In conclusion, patients had often tried to help themselves, but they needed professionals who listened and aided in eliminating their late complications. Patients were generally happy with telephone consultations and ePROMs, and telephone consultations were time saving and the patients felt they could express themselves freely. Furthermore, if incontinence was a problem, the patient would feel more secure being at home close their own toilet during the consultation. Patients needed better information about what to expect after treatment for colorectal and anal cancer, and options for basic treatment that they could initiate by themselves before attending the hospital. Thus, late complication clinics are relevant for helping patients after treatment for colorectal and anal cancer.

\section{Declarations}

Funding: $\quad$ Not applicable

Conflicts of interest/Competing interests:

Not applicable 
Availability of data and material:

Transcripts of all interviews are coded with participant ID number and stored.

Code availability: $\quad$ Not applicable

Authors' contributions: Conception and design: BTO, JR, MLH, AKD

Data acquisition: TT, MLH

Data analysis: MA, BTO, TT

First draft of the paper: BTO

Critical revision and final approval: all

Ethics approval: $\quad$ The study was approved by the Danish Data Protection Agency (P-2021-31) and was exempt from approval from the Committee of Health Research Ethics (Journal-no.: $\mathrm{H}$ 21020718). The study was done in full accordance with the Helsinki declaration.

Consent to participate: Informed consent was obtained from all individual participants included in the study.

Consent for publication: Not applicable

\section{References}

1. WHO health topics about cancer. 2021. https://www.who.int/news-room/fact-sheets/detail/cancer accessed 15 Jun 2021.

2. Nationwide database rapport about colorectal and anal cancer. 2018. Danish Colorectal Cancer Group. https://dccg.dk/wp-content/uploads/2019/09/DCCG-\%C3\%85rsrapport-2018.pdf accessed 8 Oct 2021.

3. Simard J, Kamath S, Kircher S. Survivorship guidance for patients with colorectal cancer. Curr Treat Options Oncol 2019;20:38. https://doi.org/10.1007/s11864-019-0635-4

4. Statics of rectal- and anal cancer 2016. NORDCAN, Association of the Nordic Cancer Registries. https://www-dep.iarc.fr/NORDCAN/DK/StatsFact.asp? cancer=120\&country=208 accessed 15 Jun 2021.

5. Verkuijl SJ, Jonker J, Trzpis M, Burgerhof J, Broens P, Furnée E. Functional outcomes of surgery for colon cancer: a systematic review and meta-analysis. Eur J Surg Oncol 2020;47:960-9. https://doi.org/10.1016/j.ejso.2020.11.136

6. Gilmore B, Ezekian B, Sun Z, Peterson A, Mantyh C. Urinary dysfunction in the rectal cancer survivor. Curr Bladder Dysfunct Rep 2016;11:105-12. https://doi.org/10.1007/s11884-016-0357-4 
7. Duran E, Tanriseven M, Ersoz N, Oztas M, Ozerhan I, Kilbas Z, Demirbas S. Urinary and sexual dysfunction rates and risk factors following rectal cancer surgery. Int J Colorectal Dis 2015;30:154755. https://doi.org/10.1007/s00384-015-2346-z

8. Sunesen KG, Nørgaard M, Lundby L, Havsteen H, Buntzen S,Thorlacius-Ussing O, Laurberg S. Longterm anorectal, urinary and sexual dysfunction causing distress after radiotherapy for anal cancer: a Danish multicentre cross-sectional questionnaire study. Colorectal Dis 2015;17:230-9. https://doi.org/10.1111/codi.13076

9. Mosher CE, Winger JG, Given BA, Helft PR, O'Neil BH. Mental health outcomes during colorectal cancer survivorship: a review of the literature. Psycho-oncology 2016;25:1261-70. https://doi.org/10.1002/pon.3954

10. Luo X, Li J, Chen M, Gong J, Xu Y, Li Q. A literature review of post-treatment survivorship interventions for colorectal cancer survivors and/or their caregivers. Psycho-oncology 2021;30:807-17. https://doi.org/10.1002/pon.5657

11. Shapiro CL, Charles L. Cancer survivorship. N Engl J Med 2018;15:64-70. https://doi.org/10.1007/s11654-020-00200-z

12. Tong A, Sainsbury P, Craig J. Consolidated criteria for reporting qualitative research (COREQ): A 32item checklist for interviews and focus groups. Int J Qual Heal Care 2007;19:349-57. https://doi.org/10.1097/DCR.0000000000001489

13. Coyne IT. Sampling in qualitative research. Purposeful and theoretical sampling; merging or clear boundaries? J Adv Nurs 1997;26:623-30. https://doi.org/10.1046/j.1365-2648.1997.t01-25-00999.x

14. Kvale S, Brinkmann S. Interviews - learning the craft of qualitative research interviewing. 2nd ed. Sage Publications, Inc; 2009.

15. Pedersen B, Delmar C, Falkmer U, Grønkjaer M. Bridging the gap between interviewer and interviewee: developing an interview guide for individual interviews by means of a focus group. Scand $\mathrm{J}$ Caring Sci 2016;30:631-8. https://doi.org/10.1111/scs.12280

16. Kallio H, Pietilä AM, Johnson M, Kangasniemi M. Systematic methodological review: developing a framework for a qualitative semi-structured interview guide. J Adv Nurs 2016;72:2954-65. https://doi.org/10.1111/jan.13031

17. Sandelowski MM, Polit DF, Beck CT. Sample size in qualitative research. Res Nurs Health 1995;18:179-83. https://doi.org/10.1002/nur.4770180211

18. Sandelowski M. Notes on transcription. Res Nurs Health 1994;17:311-4. https://doi.org/10.31826/9781463229955-001

19. Elo S, Kyngäs, H. The qualitative content analysis process. J Adv Nurs 2008;62:107-15. https://doi.org/10.1111/j.1365-2648.2007.04569.x

20. Declaration of Helsinki - ethical principles for medical research involving human subjects. 2018. World Medical Association. https://www.wma.net/policies-post/wma-declaration-of-helsinki-ethicalprinciples-for-medical-research-involving-human-subjects/ accessed 07 Oct 2021. 
21. Bray FN, Simmons BJ, Wolfson AH, Nouri K. Acute and Chronic Cutaneous Reactions to lonizing Radiation Therapy. Dermatol Ther. 2016;6(2):185-206. https://10.1007/s13555-016-0120-y

22. DL. Loprinzi CL, Lacchetti C, Bleeker J, Cavaletti G, Chauhan C, Hertz DL, Kelley MR, Lavino A, Lustberg MB, Paice JA, Schneider BP, Lavoie Smith EM, Smith ML, Smith TJ, Wagner-Johnston N, Hershman. Prevention and management of chemotherapy-induced peripheral neuropathy in survivors of adult cancers: American Society of Clinical Oncology clinical practice guideline. J Clin Oncol. 2014;32(18):1941-67. DOI: Hershman DL. Prevention and management of chemotherapyinduced peripheral neuropathy in survivors of adult cancers: American Society of Clinical Oncology clinical practice guideline. J Clin Oncol. 2014;32(18):1941-67. DOI: https://10.1200/JC0.2013.54.0914

23. Bratu O, Oprea I, Marcu D, Spinu D, Niculae A, Geavlete B, Mischianu D. Erectile dysfunction postradical prostatectomy - a challenge for both patient and physician. J Med Life. 2017;10(1):13-18.

24. Kræftens Bekæmpelse, barometerundersøgelse 2019. https://www.cancer.dk/dyn/resources/File/file/3/8373/1574778638/kraeftens-bekaempelsesbarometerundersoegelse-2019.pdf. accessed 10 nov 2021.

25. Carduff E, Murray SA, Kendall M. Methodological developments in qualitative longitudinal research: The advantages and challenges of regular telephone contact with participants in a qualitative longitudinal interview study. BMC Res Notes 2015;8:1-10. https://doi.org/10.1186/s13104-0151107-y

26. Novick G. Is there a bias against telephone interviews in qualitative research? Res Nurs Health. 2008;31(4):391-8. https://doi.org/10.1002/nur.20259

\section{Tables}

Table 1: Demographics. 


\begin{tabular}{|c|c|c|c|c|c|}
\hline $\begin{array}{l}\text { ID } \\
\text { number }\end{array}$ & Gender & Age & Cancer form & Symptoms* & $\begin{array}{l}\text { Number of } \\
\text { contacts }\end{array}$ \\
\hline 1 & Male & 59 & $\begin{array}{l}\text { Rectum } \\
\text { cancer }\end{array}$ & Stool & 3 \\
\hline 2 & Male & 65 & Colon caner & Stool & 2 \\
\hline 3 & Male & 75 & $\begin{array}{l}\text { Rectum } \\
\text { cancer }\end{array}$ & Stool, urine & 3 \\
\hline 4 & Male & 58 & Colon cancer & Psycho-social & 1 \\
\hline 5 & Female & 75 & Anal cancer & Stool, urine & 2 \\
\hline 6 & Female & 73 & Colon cancer & Stool & 1 \\
\hline 7 & Female & 55 & Colon cancer & Urine, psycho-social & 1 \\
\hline 8 & Male & 59 & $\begin{array}{l}\text { Rectum } \\
\text { cancer }\end{array}$ & Stool & 4 \\
\hline 9 & Male & 74 & Colon cancer & Stool, psycho-social & 3 \\
\hline 10 & Male & 56 & Anal cancer & Stool, psycho-social & 6 \\
\hline 11 & Male & 76 & $\begin{array}{l}\text { Rectum } \\
\text { cancer }\end{array}$ & $\begin{array}{l}\text { Stoll, urine, sexual, psycho- } \\
\text { social }\end{array}$ & 6 \\
\hline 12 & Male & 52 & $\begin{array}{l}\text { Rectum } \\
\text { cancer }\end{array}$ & Stool, sexual & 2 \\
\hline 13 & Female & 60 & $\begin{array}{l}\text { Rectum } \\
\text { cancer }\end{array}$ & Stool & 4 \\
\hline 14 & Male & 70 & $\begin{array}{l}\text { Rectum } \\
\text { cancer }\end{array}$ & Stool & 2 \\
\hline 15 & Female & 42 & Anal cancer & Stool & 3 \\
\hline
\end{tabular}

Demographics of participants in the interview study

*: Symptoms refer to which late complications the patient present in the clinic. Stool means stool dysfunction, urine means urine dysfunction, sexual means sexual dysfunction, and psycho-social means psycho-social distress in a broad meaning.

$\star *$ : Number of contacts refer to how many consultations the patient had in the clinic on the time for the interview.

ID number 1 dropped out before the interviews were performed leaving 14 patients for data analysis.

Table 2: Citations. 


\section{Subcategories Citation}

Participant number

How the patients got in contact with the clinic
I have been in a kind of vacuum. I did not know what was happening with me. I have these visits (at oncology department) three times a year at Herlev (name of the hospital), I tell my complaints and such things. And then suddenly she says "you know what, we will give you, that you can attend the late complication clinic".

Professional staff

It was super good, I have had really good information. Now we do so, I will call you etc. Good treatment, good guidance, and good in listening, they are too.

\section{Symptoms were} reduced for most patients after they had attended the late complication clinic

Experiences with the concept of a late complication clinic

Recommendations for the future of the clinic
I went home with a treatment plan, and then she has continuously followed up on how this treatment plan worked for me. It was very nice from the beginning to have outlined what to do next if the first step did not work. And to know I would not reach a sorry state if the first treatment did not work.
It is difficult for a person like me to keep track on whom I am supposed to contact and where I shall address a specific problem, but (with the late complication clinic) there is one gateway and then they will sort out what to do.

I would like to have advice and guidance to get started (treatment of late complication). I would also like to have advice and guidance to what I could expect. In coherency with that there should be a follow-up asking how it is going. I suppose there would be more need for follow up in the beginning than later.
Consultations by telephone
I prefer telephone consultation because I think it is so troublesome to come to Herlev (name of the hospital). Yes, because then I only spend one hour, or half an hour if the consultation last that long. Otherwise I could spend the entire morning.

Experiences with ePROMS
If I had the same questions before my surgery for cancer it would have crossed my personal boundary to answer, but it was in fact nice to have the possibility to answer in so much detail.

There is one citation for every subcategory. The citations are translated into English. The participant ID number is shown next to the citation.

\section{Figures}




\section{Benefitting from the late complication clinic}

- How the patients got in contact with the clinic

- Professional staff

- Symptoms were reduced for most patients after they had attended the late complication clinic

- Experiences with the concept of a late complication clinic

- Recommendations for the future of the clinic

\section{Preparation \\ and delivery \\ of the \\ consultations}

- Consultations by telephone

- Experiences with ePROMS

\section{Figure 1}

Main categories as well as subcategories for patients' experiences with the late complication clinic.

\section{Supplementary Files}

This is a list of supplementary files associated with this preprint. Click to download.

- COREQtjekliste.docx 